\title{
TREE NUMBER ESTIMATION WITH THE USE OF VHR NATURAL COLOR ORTHOPHOTOS OVER A HETEROGENEOUS LANDSCAPE IN NORTHERN GREECE
}

\author{
P. Stournara ${ }^{\text {a, } *, \text { M. Tsakiri-Strati }}{ }^{\text {a }}$, S. Siachalou ${ }^{\text {a }}$, G. Doxani ${ }^{\text {a }}$, G. Mallinis ${ }^{\text {b }}$, V. Tsioukas ${ }^{\text {a }}$ \\ ${ }^{a}$ Aristotle University of Thessaloniki (AUTH), School of Rural and Surveying Engineering, Greece - \\ (pstour, martsaki, ssiacha, gdoxani, tsioukas)@ topo.auth.gr, \\ ${ }^{\mathrm{b}}$ Democritus University of Thrace (DUTH), Department of Forestry and Management of the Environment and Natural Resources, \\ Orestiada, Greece - gmallin@fmenr.duth.gr
}

Commission VI, WG VI/4

KEY WORDS: VHR orthophotos, Forest management, Tree number, Tree crown detection, Local Maxima

\begin{abstract}
:
Spatial explicit knowledge regarding the quantity and the spatial distribution of forest parameters is crucial for sustainable forest management, as well as in fulfilling national reporting needs in the framework of international treaties (i.e. Kyoto Protocol, FAO, EFFIS etc). Especially, tree number which can be used for assessing forest tree density (tree number/ha), is among the most important and laboursome parameters to be measured in the field. The aim of this study is to estimate tree number based on the use of nationwide, freely available, very high spatial resolution orthophotos acquired from Greek National Cadastre and Mapping Agency during the 2007-2009 period. The study area is the University Forest of Taxiarchis, which is located in central Halkidiki, Northern Greece. The dominant species of the forest includes both broadleaves (oak, beech) and coniferous species (Black pine, Calabrian pine), which are found in both pure and mixed stands. Tree crown detection was tested on natural color orthophoto bands in several plots. The principal components and intensity-hue-saturation transformations were also applied in order to enhance tree detection accuracy. Local maxima technique was utilized for tree crown detection. Accuracy results were evaluated based on field plot data available from the official forest management plan of the area completed in 2011. Overall, the detection accuracy exceeded $50 \%$ which is deemed satisfactory considering also the heterogeneity of the Mediterranean landscape and the limited spectral resolution of the remote sensing data available.
\end{abstract}

\section{INTRODUCTION}

Forest structural parameters such as tree diameter, basal area and number of trees per unit area are important for the assessment of wood volume and biomass and represent key forest inventory attributes. Forest inventory information is required to support sustainable management, carbon accounting, and policy development activities (Gómez et al., 2012).

Remote sensing has potential to provide, at lower cost, robust forest information with greater coverage and more limited time extent than is attainable using field sampling. However, forest areas in the Mediterranean region are known for the high spatiotemporal heterogeneity of their vegetation patterns with respect to species composition and stand (Salvador and Pons 1998; Shoshany, 2000). While this heterogeneity makes them aesthetically attractive, accurate mapping of these areas has been the weak point of applied remote sensing technology, especially for local scale mapping (Mallinis et al., 2008).

Very high resolution (VHR) remote sensing imagery can provide a viable source for effective, automated analyses for providing necessary forest information by extracting single tree information. This requires identification of individual trees and subsequent analysis of tree parameters such as species (Leckie et al., 2005).

Several automated and semi-automated methods to identify and map individual trees using remotely sensed data have been proposed in the literature. Most utilize the common phenomenon that, on high resolution imagery, trees generally appear as bright objects surrounded by darker shaded areas (Leckie et al., 2005).

A variety of approaches to tree detection exist such as the template matching method, where a series of models are constructed to characterize what a tree looks across an image, the valley-following method, the edge detection method which evaluates the occurrence of edges over several image scales to identify representative location of the tree peak and local maxima filtering. The local maxima (LM) filtering is a technique that has been adapted to the detection of individual trees, considering that large digital numbers correspond to the tree peak. A local maximum is identified where the magnitude of the digital number of a pixel is greater than all the surrounding neighbours, within a window of specified size (Wulder et al., 2004).

The aim of this study is the evaluation of such an approach based on LM over a heterogeneous Mediterranean forest landscape using VHR natural color orthoimagery acquired from Greek National Cadastre and Mapping Agency during the period of 2007-2009.

\section{STUDY AREA AND DATASETS}

\subsection{Study area}

The study area is the University Forest of Taxiarchis, which is located in central Halkidiki, Northern Greece. Figure 1 presents

* Corresponding author 
the geographical location of the University Forest and its boundaries. The tree species of forested study area is both coniferous and broadleaf and specifically are calabrian pine (Pinus brutia), black and maritime pine (Pinus nigra and Pinus maritima), oak (Quercus confertae) and beech (Fagus moesiaca). Also there exists and lower vegetation (broadleaf evergreen).

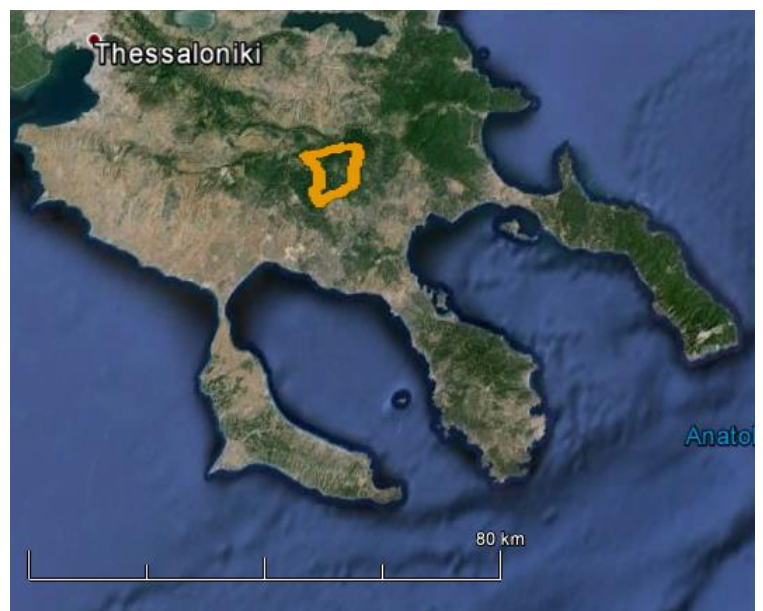

Figure 1. Geographical location of the University Forest Taxiarchis of Halkidiki is presented. (c) Google Earth, Copyright 2015.

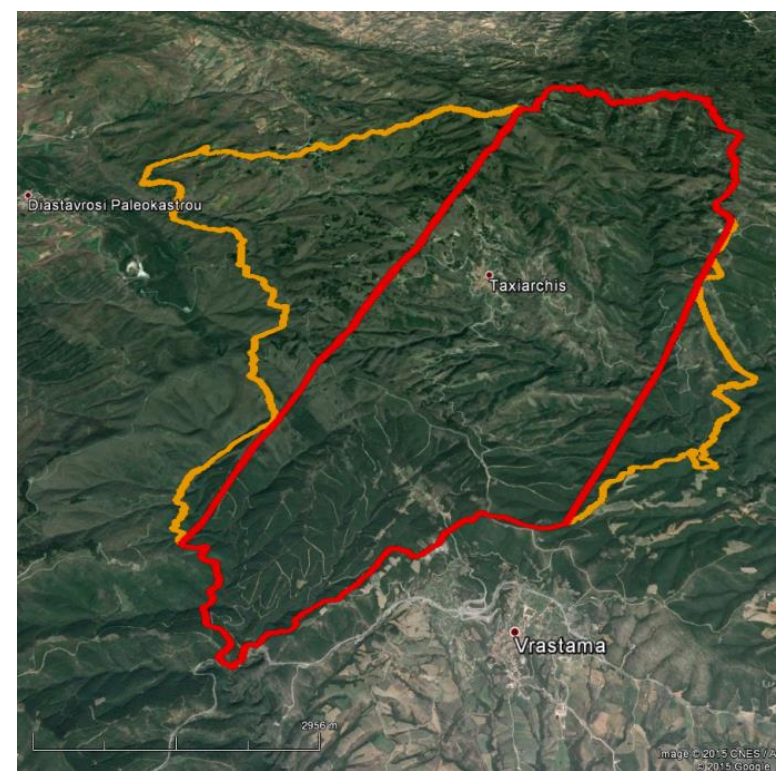

Figure 2. The University Forest of Taxiarchis (orange frame) and the area on which this study has focused (red frame) are presented. (c) Google Earth, Copyright 2015.

\subsection{Datasets}

The image dataset used in this study was in large scale true color orthophotos (LSO) with $0.50 \mathrm{~m}$ spatial resolution, which were provided by the Greek National Cadastre and Mapping Agency. They were acquired during the 2007-2009 period using a Zeiss RMK Top airborne digital camera system under the Hellenic National Cadastre campaign (Kavvadas \& Karabelas). The orthophotos were georeferenced in the Hellenic Positioning System (HEPOS), which was designed and implemented by the Greek National Cadastre and Mapping Agency, in order to provide positioning services utilizing the existing Global
Positioning System (Greek National Cadastre and Mapping Agency, 2009).

The field plot data (official forest management plan that completed in 2011) included tree number by species and it was provided by the Administration and Management Fund of the University Forest. Plot surfaces (cyclical of $10 \mathrm{~m}$ radius and of 0.031 ha extent), provided in vector format, were georeferenced in the Hellenic Geodetic Reference System 1987 (EGSA87). On the south part of the true orthophotos (Figure 3) the dominant tree species is calabrian pine, while maritime pine is present in much less extent. On the north part beech and black pine exist. In the central part, the dominant tree species is oak. Unfortunately, due to winter-acquired airphotos, broadleaf oaks have lost their foliage and are not recognizable.

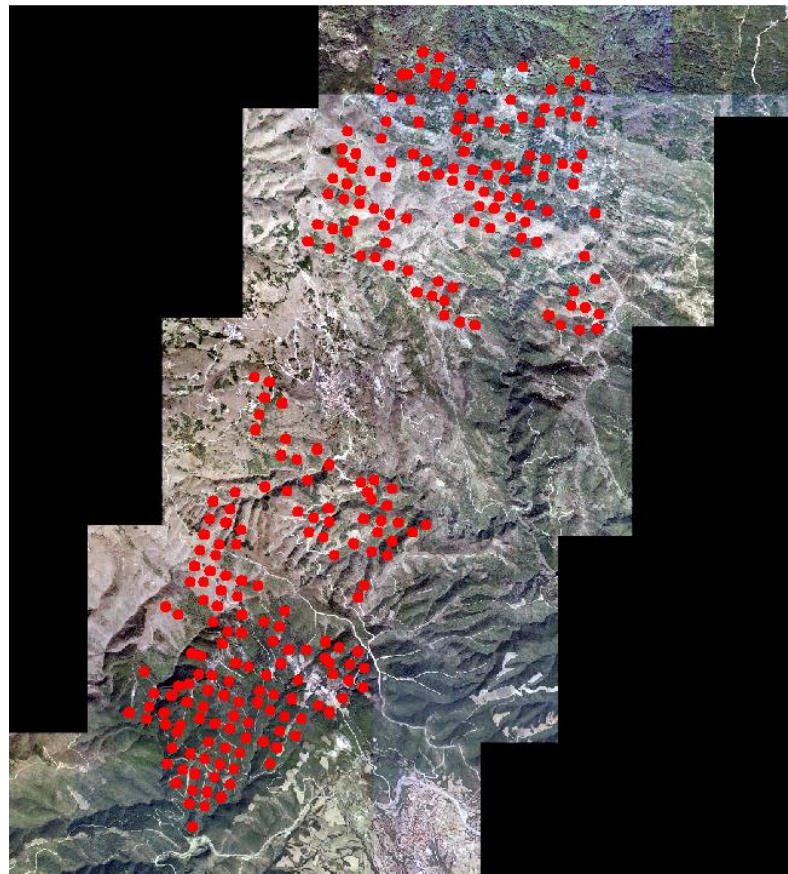

Figure 3. The VHR orthophotos used in this study superimposed by the plot surfaces of the field data are presented. (C) Greek National Cadastre and Mapping Agency, Copyright 2007-2009.

\section{METHODOLOGY}

\subsection{Overall process}

The overall process of the study is given in Figure 4.

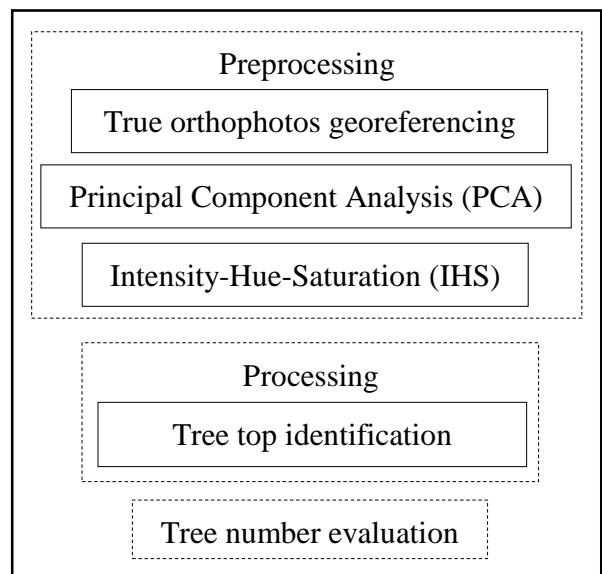

Figure 4. Flowchart of the overall process. 


\subsection{Data preprocessing}

The large scale true colour orthophotos were mosaicked into one image and georeferenced from the HEPOS to the EGSA87 coordinate system, in order to be used simultaneously with the plot surfaces. The 1st order polynomial (affine) transformation was utilized and the RMS error was less than $0,10 \mathrm{~m}$.

The true orthophotos were separated into individual bands, for the purpose of comparing the results between them. Also, the PCA and IHS transformations were applied, in order to enhance tree detection accuracy. The PCA transformation reduces the image dimensionality through image compression, gathering most of the valuable information in the first band. The PCA bands are often more interpretable than the source data because they are not correlated between them (Doxani et al., 2008). The IHS transformation separates the spatial information (Intensity component) from the spectral information (Hue and Saturation components) (Koutsias et al., 2000).

\subsection{Tree Top identification}

The local maxima technique was utilized to detect tree tops and determine the number of trees (Figures 5 and 6). It is based on the consideration that tree tops correspond to bright peaks in the remote sensing image due to the higher level of illumination compared to the rest parts of the tree (Ke et al., 2010). This fits better to conical structure trees. In this study it was applied to conifers and broadleaves, in order to test its applicability and robustness.

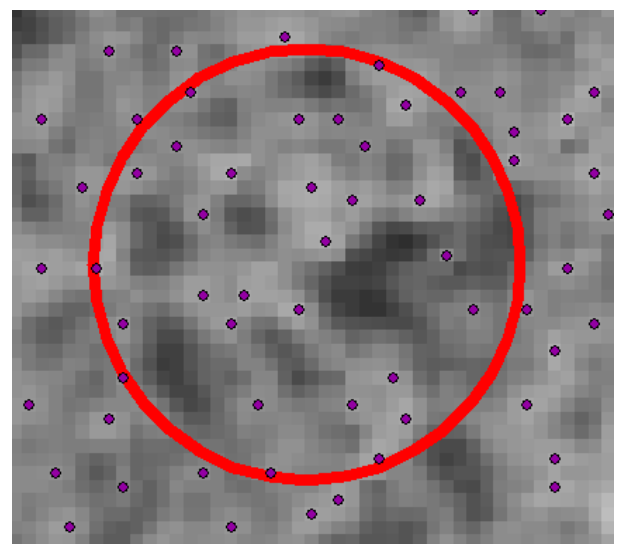

Figure 5. Local maxima detected from the implementation of the automatic procedure on the red band, superimposed on the same band (plot ID 8, Calabrian pine).

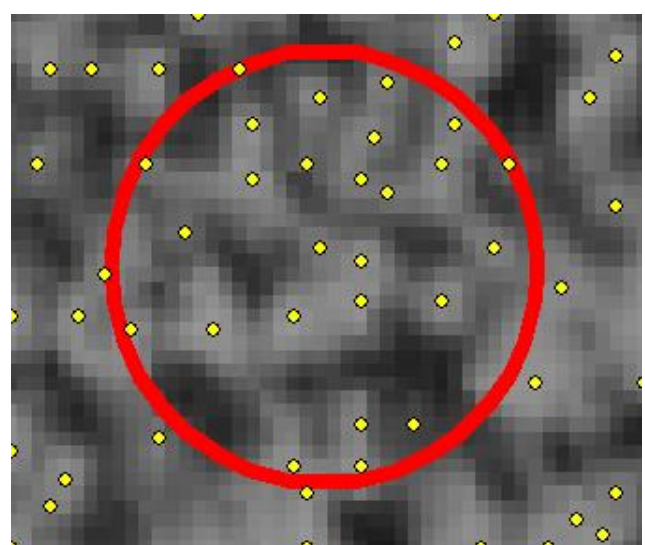

Figure 6. Local maxima detected from the implementation of the automatic procedure on the green band, superimposed on the same band (plot ID 9, Calabrian pine).

\section{RESULTS}

The accuracy evaluation was implemented by counting and comparing the number of trees in the various bands for several number of plots. Photointerpretation was utilized in the counting of trees (Figure 7). More calabrian pine plots were available, so more plots from this species were utilized. From the IHS transformation only the intensity band was useful. The hue and saturation bands didn't give good results, so they weren't included for further evaluation. In Table 1 results for the red $(\mathrm{R})$, green $(\mathrm{G})$, blue $(\mathrm{B}), 1^{\text {st }}$ PCA and intensity (I) bands are presented. Reference data are the field data.

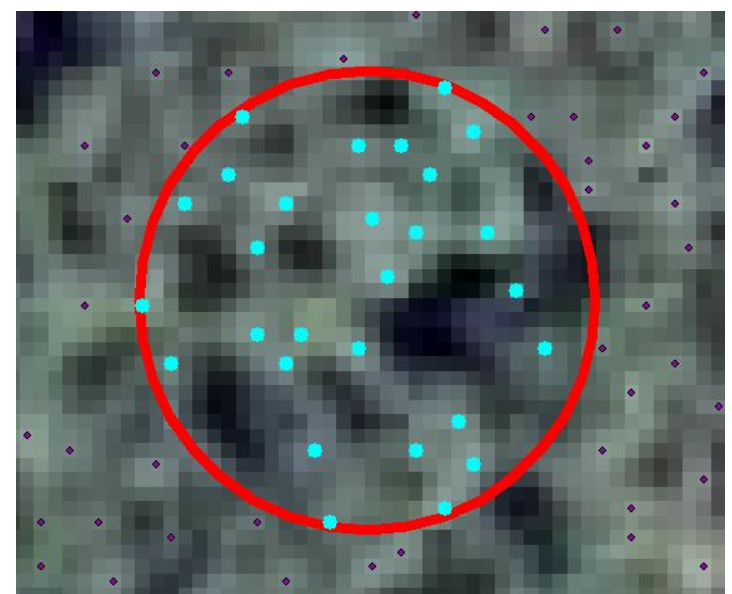

Figure 7. The evaluation procedure. Plot ID 8 and results from the red band. 28 tree tops have been counted, while according to reference data, trees are 25 .

\begin{tabular}{|c|c|c|c|c|c|c|c|}
\hline $\begin{array}{c}\text { Plot } \\
\text { ID }\end{array}$ & Tree species & $\begin{array}{c}\text { Field } \\
\text { data }\end{array}$ & R & G & B & PCA-1 & I \\
\hline 8 & P. brutia & $\mathbf{2 5}$ & 28 & 28 & 30 & 29 & 29 \\
\hline 9 & P. brutia & $\mathbf{2 2}$ & 22 & 23 & 20 & 23 & 20 \\
\hline 21 & P. brutia & $\mathbf{3 7}$ & 29 & 29 & 32 & 30 & 31 \\
\hline 22 & P. brutia & $\mathbf{2 6}$ & 21 & 23 & 24 & 24 & 24 \\
\hline 24 & P. brutia & $\mathbf{4 1}$ & 41 & 41 & 41 & 41 & 40 \\
\hline 34 & P. brutia & $\mathbf{4 9}$ & 29 & 28 & 29 & 30 & 30 \\
\hline 36 & P. brutia & $\mathbf{5 2}$ & 33 & 34 & 38 & 35 & 35 \\
\hline 40 & P. brutia & $\mathbf{3 3}$ & 30 & 27 & 35 & 31 & 31 \\
\hline 41 & P. brutia & $\mathbf{4 2}$ & 29 & 29 & 29 & 28 & 28 \\
\hline 46 & P. brutia & $\mathbf{3 5}$ & 30 & 27 & 30 & 30 & 29 \\
\hline 47 & P. brutia & $\mathbf{3 3}$ & 28 & 26 & 27 & 27 & 27 \\
\hline 50 & P. brutia & $\mathbf{2 6}$ & 30 & 29 & 32 & 30 & 31 \\
\hline 66 & P. brutia & $\mathbf{2 8}$ & 29 & 29 & 29 & 31 & 30 \\
\hline 67 & P. brutia & $\mathbf{2 5}$ & 30 & 29 & 32 & 32 & 32 \\
\hline 97 & P. brutia & $\mathbf{2 6}$ & 28 & 28 & 30 & 28 & 29 \\
\hline 121 & P. brutia & $\mathbf{2 5}$ & 29 & 29 & 29 & 29 & 29 \\
\hline 704 & P. nigra & $\mathbf{3 1}$ & 33 & 32 & 33 & 34 & 33 \\
\hline 740 & P. nigra & $\mathbf{2 3}$ & 26 & 26 & 27 & 26 & 27 \\
\hline 753 & P. nigra & $\mathbf{3 9}$ & 25 & 25 & 26 & 25 & 25 \\
\hline 16 & P. maritima & $\mathbf{3 1}$ & 29 & 28 & 30 & 29 & 29 \\
\hline 729 & F. moesiaca & $\mathbf{2 3}$ & 23 & 23 & 24 & 22 & 24 \\
\hline 774 & F. moesiaca & $\mathbf{4 1}$ & 35 & 32 & 33 & 14 & 35 \\
\hline 775 & F. moesiaca & $\mathbf{3 4}$ & 32 & 28 & 30 & 10 & 31 \\
\hline 789 & F. moesiaca & $\mathbf{3 7}$ & 36 & 34 & 35 & 17 & 35 \\
\hline 791 & F. moesiaca & $\mathbf{4 1}$ & 35 & 31 & 30 & 2 & 31 \\
\hline & T 1 The best & $29+6$ & & \\
\hline
\end{tabular}

Table 1 . The best performance in each plot is marked. 


\section{DISCUSSION AND CONCLUSIONS}

Overall, all bands performed quite satisfactory as the tree detection accuracy exceeded 50\%. These results are remarkable considering the heterogeneity of the Mediterranean landscape and the limited spectral resolution of the remote sensing data available. The best performance in each plot is marked in Table 1. Therefore, it can be easily noticed that reference tree numbers around 50 are not possible to be reached by the automatic procedure. This is probably due to existence of younger trees, not recognizable by the airphotos. The red, green, blue and intensity bands are quite close in performance, but the red and the green bands are slightly better. The PCA band has good results in conifer species, but poor results in broadleaf species.

\section{ACKNOWLEDGEMENTS}

We gratefully acknowledge University Forest Administration and Management Fund for providing forest field data and the Greek National Cadastre and Mapping Agency for providing the image dataset. This research has received funding by the European Union (European Social Fund-ESF) and Greek national funds through the Operational Program "Education and Lifelong Learning" of the National Strategic Reference Framework (NSRF) Research Funding Program: THALES. The authors wish to thank for the financial support of the $36^{\text {th }}$ ISRSE Organizing Committee travel support program.

\section{REFERENCES}

Doxani, G., Siachalou, S. and Tsakiri-Strati, M., 2008. An object-oriented approach to urban land cover change detection. In: The International Archives of the Photogrammetry, Remote Sensing and Spatial Information Sciences, Beijing, China, Vol. XXXVII, Part B7, pp. 1655-1660.

Gómez, C., Wulder, M.A., Montes, F. and Delgado, J.A., 2012. Modeling Forest Structural Parameters in the Mediterranean Pines of Central Spain using QuickBird-2 Imagery and Classification and Regression Tree Analysis (CART). Remote Sensing, 4(1), pp. 135-59.

Greek National Cadastre and Mapping Agency, 2009. General Information on HEPOS, http://www.hepos.gr/ (10 March 2015).

Karabelas, E., 2008. Use of HEPOS in the production of LSO/VLSO. Presentation of KTIMATOLOGIO SA Workshop "HEPOS and modern geodetic reference systems-Theory and implementation, perspectives and applications", Thessaloniki, Greece http://www.hepos.gr/ (10 March 2015).

Kavvadas, I., 2010. Cartographic Base of National Cadastre, Presentation of Technical Chamber of Greece-Regional Section of Central Macedonia in "I cycle short term Seminars: National Cadastre", Thessaloniki, Greece.

Ke, Y., Zhang, W. and Quackenbush, L.J., 2010. Active Contour and Hill Climbing for Tree Detection and Delineation. Photogrammetric Engineering \& Remote Sensing, 76(10), pp. 1169-1181.

Koutsias, N., Karteris, M. and Chuvieco, E., 2000. The use of Intensity-Hue-Saturation transformation of Landsat-5 Thematic mapper data for burned land mapping. Photogrammetric Engineering \& Remote Sensing, 66(7), pp. 829-839.

Leckie, D.G., Gougeon, F.A., Tinis, S., Nelson, T., Burnett, C.N. and Paradine, D., 2005. Automated tree recognition in old growth conifer stands with high resolution digital imagery. Remote Sensing of Environment, 94(3), pp. 311-26.

Mallinis, G., Koutsias, N., Tsakiri-Strati, M. and Karteris, M., 2008. Object-based classification using Quickbird imagery for delineating forest vegetation polygons in a Mediterranean test site. ISPRS Journal of Photogrammetry and Remote Sensing, 63 (2), pp. 237-50.

Salvador, R. and Pons, X., 1998. On the applicability of Landsat TM images to Mediterranean forest inventories. Forest Ecology and Management, 104(1-3), pp. 193-208.

Shoshany, M., 2000. Satellite remote sensing of natural Mediterranean vegetation: A review within an ecological context. Progress in Physical Geography, 24(2), pp. 153-78.

Wulder, M.A., White, J.C., Niemann, K.O and Nelson, T., 2004. Comparison of airborne and satellite high spatial resolution data for the identification of individual trees with local maxima filtering. International Journal of Remote Sensing, 25(11), pp. 2225-2232. 